\title{
Prediction of Anaemia using Unenhanced Computed Tomography of Thorax: A Cross-sectional Study
}

\section{ABSTRACT}

Introduction: Anaemia is a widespread problem and although Computed Tomography (CT) is not the primary modality to diagnose anaemia as it is possible to easily obtain the haemoglobin estimation levels, which is a direct measure for the degree of anaemia. However, it is possible to detect certain changes on CT that point towards anaemia. It is important to identify incidental findings as it can have a direct effect on the management and outcome.

Aim: The aim of the present was to evaluate the role and accuracy of unenhanced CT thorax in prediction of anaemia.

Materials and Methods: This was a cross-sectional study on a total of 100 cases. All the patients who underwent thoracic/ abdominal CT in Department of Radiodiagnosis and Imaging in Father Muller Medical College and Hospital, Kankanady, Manglore, India were included as subjects from July 2019 to September 2019. The normal reference blood haemoglobin level was taken as $14 \mathrm{~g} / \mathrm{dL}$ and $11 \mathrm{~g} / \mathrm{dL}$ in the male and the female population respectively. The peripheral blood examination was done within 24 hours after or before an unenhanced CT scan. Sixteen slice CT scanner was used for the study. Frequency, percentage, mean, Standard Deviation (SD), Positive Predictive Value (PPV), Negative Predictive Value (NPV) was used in statistical analysis of data. Chi-square/Fisher's Exact test was used and $p$-value $<0.05$ is considered to be significant.

Results: This was a female predominant study consisting of 53 females of sample size. A total of $59 \%$ patients were diagnosed to have anaemia by blood parameters. A total of $61 \%$ patients were detected to have the aortic ring sign whereas $65 \%$ of the patients were detected with hyperdense Interventricular (IV) septum sign.

Conclusion: Whenever the interventricular septum is seen on a CT thorax without contrast, it suggests the presence of underlying anaemia and it needs to be evaluated so as to improve the management and reduce the morbidity to the patient.

\section{INTRODUCTION}

The CT assessment of the chest and various sites of body regularly create coincidental discoveries. One such coincidental conclusion that can be made is of anaemia. In any case, haemoglobin deficiency i.e., anaemia isn't fundamentally established on CT as plasma haemoglobin levels can be acquired promptly, it is regularly seen that in most cases where the diagnosis is in doubt, it may incite a CT assessment. Not withstanding the wide scope of clinical significance of CT, recognising such incidental discoveries, particularly in emergency settings as it helps in providing the best possible management to the patient [1].

It is possible to even comment on the blood viscosity within the chambers of the heart and in the blood vessels in an unenhanced CT which is taken for other conditions, and through these findings it may be possible to predict anaemia. But this is not possible by all radiologists as it needs an eagle's eye. Powell Jr WJ et al., stated that when the CT of the canines were evaluated, they observed that the cavities of the cardiac chambers become clearly visible as a result of which it is possible to easily differentiate the margins of the atrial and ventricular cavities, papillary muscles, major trabeculae and the aorta [2].

Previously, anaemia used to be diagnosed with the aortic ring sign, which implies that when the hyperdense aortic wall is seen against relative hypoattenuating aortic blood pool, or with the "IV septum sign" i.e., when the dense myocardium or IV septum is clearly visualised on non contrast CT against hypodense Left Ventricular (LV) cavity $[3,4]$. Such observations are a reliable method in detecting severe anaemia, but these are observer dependent processes [4] which may be subject to significant interobserver variability.

Some authors stress on the usefulness of CT attenuation of abdominal aorta while some emphasise on the difference of CT attenuation between the Left Ventricular (LV) cavity and the IV septum. However, the best method to analyse this relation, and also its reliability is not certain [5].

The CT measurement parameters in the occurrence of anaemia includes:

1. CT numbers of the thoracic or the abdominal aorta,

2. Inferior Vena Cava (IVC), LV cavity,

3. The Interventricular Septum sign

4. The attenuation difference between the LV cavity and IVS [6]

One of the consistent sign in the diagnosis of anaemia is the ability to distinguish the myocardium or IVS as both of them are relatively dense structures from a hypodense LV cavity [3]. However, this approach has been shown recently to be an operator dependent process which may be subject to significant interobserver variability [4].

Research has also shown that in some of the conditions when the haemoglobin levels are normal, there may be a false sign of increase IV density on CT because of the increased iron or glycogen content as noticed in haemochromatosis and glycogen storage disorders [3]. Likewise, the finding of a hyperdense aortic wall has been used for diagnosing an underlying anaemia, but the drawback is that, this is seen when there are existing calcified atherosclerotic plaques $[3,7]$. In contrast, the objective analysis is a more accurate process [5] which can differentiate the anaemic from the non anaemic subjects, which can be established by analysing the density of blood pool of great vessels or the cardiac chambers on unenhanced CT. In $\mathrm{CT}$, a number is assigned by the computer for materials and water having different $X$-ray attenuation to differentiate between them. It is measure of CT density and called as Hounsfield Units $(\mathrm{HU})$ and it ranges between $-1,000$ and 1,000 (for example: air is equal to $1,000 \mathrm{HU}$ and pure water is equal to $0 \mathrm{HU}$ ). 
This number in turn is used by the computer to assign a gray scale shade to the corresponding image [5]. Di Giandomenico E et al., showed that there is significant difference in blood attenuation values between healthy subjects and the anaemic patients by CT density measurements of intravascular blood [8].

The purpose of this study was to evaluate the role and accuracy of unenhanced CT thorax in predicting anaemia by demonstrating a correlation between the attenuation value of IVS and routine haematological assay of haemoglobin level on unenhanced CT examination. The study also evaluates if measurement of Hounsfield units $(\mathrm{HU})$ of the lumen of IVS evaluation is sufficiently accurate in predicting anaemia.

\section{MATERIALS AND METHODS}

It was a cross-sectional study done on 100 patients, who underwent thoracic/abdominal CT in Department of Radiodiagnosis and Imaging in Father Muller Medical College and Hospital, Kankanady, Mangalore, Karnataka, India from July 2019 to September 2019. Ethical clearance was taken from the Institute (FMIEC/CCM/154/2020).

Sample size calculation: It was done by following formula

$$
\mathrm{n}=\frac{2_{(Z \alpha+Z \beta)}+3}{\mathrm{C}^{2}}
$$

$Z \alpha=1.96$ at $95 \%$ confidence interval, $Z \beta=0.841$ at $80 \%$ power, $\mathrm{C}=0.5 \mathrm{Cn}(1+r),(1-r), r[4]=0.60, n=90$ at $80 \%$ power

Minimum sample required was 90.

Inclusion criteria: Any patient (both male and non pregnant female) between age 18-80 years who underwent non enhanced CT of thorax for any indication were included in the study.

Exclusion criteria: Previously diagnosed of anaemia or those receiving blood transfusion for anaemia were excluded from the study.

\section{Study Procedure}

The normal reference blood haemoglobin level was taken as $14 \mathrm{~g} / \mathrm{dL}$ in males and $11 \mathrm{~g} / \mathrm{dL}$ in females. The plasma haemoglobin samples were taken within 24 hours after or before an unenhanced CT scan. GE Bright speed 16 slice CT scanner was used for the study. For every patient, variables taken into the consideration were age, gender of the patient along with the presence or absence of: a) IVS i.e., "IVS sign" was taken against hypodense LV cavity; and b) hyperdense aortic wall i.e., "aortic ring sign" was taken against relatively hypoattenuating aortic blood pool. All the CT examinations were interpreted by a single assessor with an experience of three years in the Radiology Department. The assessor was not informed about the status of the serum haemoglobin levels of the patients at the time of data collection. During interpretation, soft tissue window was used in all the patients (WW:200 HU; WL:75 HU). A standard circular Region of Interest (ROI) measuring $0.25 \mathrm{~cm}^{2}$ had been applied for whole study.

The cases that were considered to be true positive are the ones that have positive findings that point towards anaemia correctly both on the CT and on haemoglobin estimation. The cases that were considered to be true negative are the ones that have positive findings that point to no anaemia on CT and on haemoglobin estimation the levels also identify no anaemia.

The cases that were considered to be false positive are the ones that have findings of positive findings that point towards anaemia on the CT wrongly and on haemoglobin estimation the levels identify no anaemia. The cases that were considered to be false negative are the ones that have positive findings that do not have anaemia findings on CT and on haemoglobin estimation, the levels identify anaemia.

\section{STATISTICAL ANALYSIS}

The data was analysed by Statistical Package for the Social Sciences (SPSS) statistical software version 21.0 was used for analysis of Positive Predictive Value (PPV), Negative Predictive Value (NPV).
Continuous variables are presented in mean and standard deviation (SD). Chi-square test/Fisher's-exact test was applied for categorical variables presented in frequency and percentages. The $p$-value $<0.05$ and $r$-value $>0.50$ was considered as significant.

\section{RESULTS}

For the presence of anaemia, 100 CT thorax were examined by the IVS and aortic ring sign objectively. Average HU of each CT thorax was also measured to deduce a cut off for the presence of anaemia. This study consisted of 59\% of the total patients diagnosed with anaemia and $53 \%$ of total were females. More number of patients (65\%) were identified to have hyperdense IV septum sign as compared to aortic ring sign [Table/Fig-1].

\begin{tabular}{|l|l|c|c|}
\hline \multicolumn{2}{|l|}{ Parameters } & Count (n) & Percentages (\%) \\
\hline \multirow{4}{*}{ Anaemia } & Present & 59 & 59 \\
\cline { 2 - 4 } & Absent & 41 & 41 \\
\hline \multirow{4}{*}{ Age (in years) } & 30 and below & 9 & 9 \\
\cline { 2 - 4 } & $31-50$ & 36 & 36 \\
\cline { 2 - 4 } & $51-70$ & 45 & 45 \\
\cline { 2 - 4 } & Above 70 & 10 & 10 \\
\hline \multirow{3}{*}{ Gender } & Female & 53 & 53 \\
\cline { 2 - 4 } & Male & 47 & 47 \\
\hline \multirow{3}{*}{ Intervetricular septum } & Present & 61 & 61 \\
\cline { 2 - 4 } & Absent & 39 & 39 \\
\hline \multirow{2}{*}{ [Table/Fig-1]: Frequency distribution of variables (N=100). } & Present & 65 & 65 \\
\cline { 2 - 4 } & Absent & 35 & 35 \\
\hline
\end{tabular}

Analysis was done based on frequency, percentage, mean, Karl Pearson's coefficient of correlation (SD), PPV, NPV. This was a female predominant study, consisting of 53 patients of sample size, with $59 \%$ of the total patients were diagnosed to have anaemia by blood parameters [Table/Fig-1]. More number of patients was identified to have hyperdense IVS sign as compared to patients having the aortic ring sign [Table/Fig-1].

Amongst the patients with positive aortic ring sign, 11 patients were misdiagnosed to have anaemia (false positive) and nine patients with anaemia were not diagnosed to have anaemia i.e., did not demonstrated the aortic ring sign. Likewise, the patients with hyperdense IVS sign were misdiagnosed to have anaemia (false positive) and few patients with anaemia did not demonstrated the hyperdense IVS sign (false negative). The sensitivity, specificity, PPV, NPV and accuracy of the hyperdense IVS sign was found to be better than that in comparison to aortic ring sign [Table/Fig-2,3].

\begin{tabular}{|c|c|c|}
\hline \multicolumn{3}{|c|}{ Interventricular septum } \\
\hline Parameters & Percentages (\%) & $95 \% \mathrm{Cl}$ \\
\hline Sensitivity & 96.61 & $88.29 \%$ to $99.59 \%$ \\
\hline Specificity & 80.49 & $65.13 \%$ to $91.18 \%$ \\
\hline Positive LR & 4.95 & 2.65 to 9.24 \\
\hline Negative LR & 0.04 & 0.01 to 0.17 \\
\hline PPV & 87.69 & $79.25 \%$ to $93 \%$ \\
\hline NPV & 94.29 & $80.73 \%$ to $98.48 \%$ \\
\hline Accuracy & 90 & $82.38 \%$ to $95.10 \%$ \\
\hline \multicolumn{3}{|c|}{$\begin{array}{l}\text { [Table/Fig-2]: Prediction of anaemia as determined by visualisation of Interventricular } \\
\text { Septum (IVS). } \\
\text { Cl: Confidence interval; LR: Likelihood ratio; PPV: Positive predictive value; NPV: Negative predictive } \\
\text { value }\end{array}$} \\
\hline
\end{tabular}

The odds ratio of hyperdense IVS sign was 117.563 (p-value <0.001) in comparison to aortic ring sign which was calculated as 15.152 (p-value <0.001) [Table/Fig-4,5].

For aortic ring sign, the value of $r$ was 0.584 . There is a tendency for high anaemia variable scores to go with high aortic ring 


\begin{tabular}{|l|c|c|}
\hline \multicolumn{3}{|c|}{ Aortic ring } \\
\hline Parameters & Value & $95 \% \mathrm{Cl}$ \\
\hline Sensitivity & $84.75 \%$ & $73.01 \%$ to $92.78 \%$ \\
\hline Specificity & $73.17 \%$ & $57.06 \%$ to $85.78 \%$ \\
\hline Positive LR & 3.16 & 1.88 to 5.30 \\
\hline Negative LR & 0.21 & 0.11 to 0.39 \\
\hline PPV & $81.97 \%$ & $73.05 \%$ to $88.40 \%$ \\
\hline NPV & $76.92 \%$ & $63.98 \%$ to $86.22 \%$ \\
\hline Accuracy & $80 \%$ & $70.82 \%$ to $87.33 \%$ \\
\hline
\end{tabular}

[Table/Fig-3]: Prediction of anaemia as determined by visualisation of aortic ring. Cl: Confidence Interval; LR: Likelihood ratio; PPV: Positive predictive value; NPV: Negative predictive value

\begin{tabular}{|l|c|}
\hline $\begin{array}{l}\text { Anaemia (Absent/Present) with following } \\
\text { parameters }\end{array}$ & $\begin{array}{c}\text { p-value } \\
\text { (Chi-square/Fishers-exact test) }\end{array}$ \\
\hline Age & 0.390 \\
\hline Gender & 0.032 \\
\hline Aortic Ring & $<0.001^{\star}$ \\
\hline Intervetricular Septum & $<0.001^{*}$
\end{tabular}

[Table/Fig-4]: Prediction of anaemia based on age, gender and radiographic signs. * $\mathrm{p}$-value $<0.05$ is significant

\begin{tabular}{|l|c|c|c|}
\hline \multicolumn{4}{|c|}{ Risk estimate } \\
\hline \multirow{2}{*}{ Odds ratio values } & \multirow{2}{*}{ Value } & Lower & Upper \\
\cline { 3 - 4 } & 0.409 & 0.179 & 0.932 \\
\hline Gender (F/M) & 15.152 & 5.628 & 40.793 \\
\hline Aortic ring (Present/Absent) & 117.563 & 23.553 & 586.794 \\
\hline Intervetricular septum (Present/Absent) & 17 . \\
\hline
\end{tabular}

variable scores vice versa with $p$-value $<0.00001$ considered to be significant. For IV septum, the value of $r$ was 0.795 which shows high anaemia variables scores with $\mathrm{p}$-value $<0.00001$ considered to be significant.

The ROC curve showed a larger area under the curve for hyperdense IVS sign in comparison to aortic ring sign. The cut off calculated by the ROC curve for hyperdense IVS sign is $38.15 \mathrm{HU}$ and for aortic ring sign is $38.5 \mathrm{HU}$ [Table/Fig-6,7].

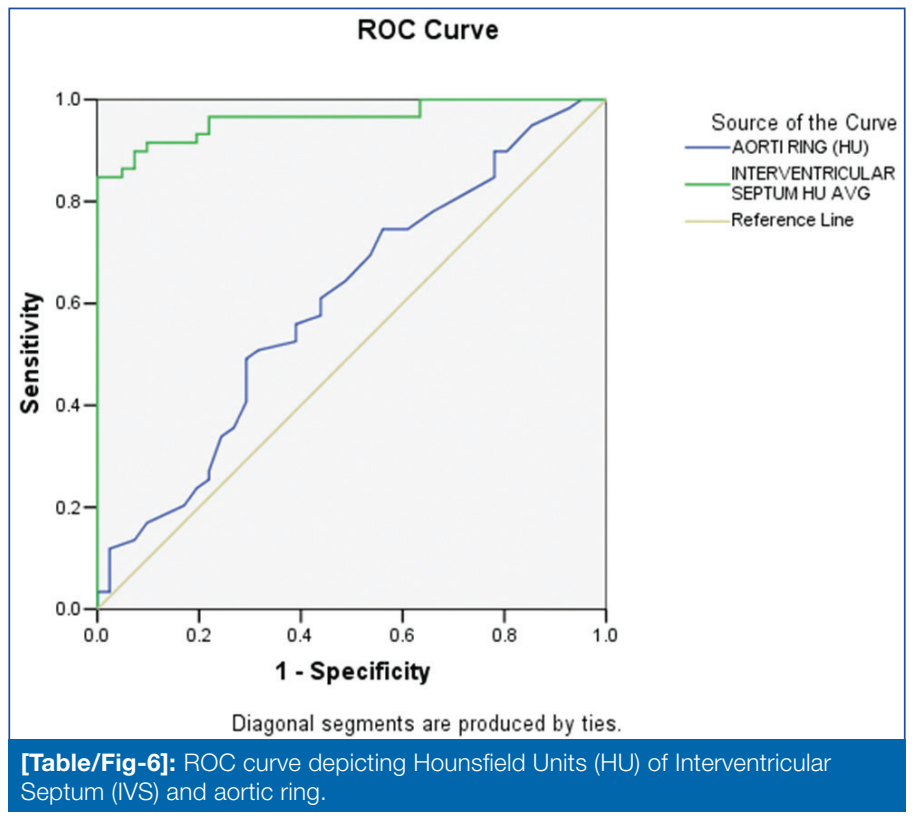

A 62-year-old male patient with severe anaemia (8.2 g/dL) showed unenhanced CT thorax findings which were conclusive of anaemia [Table/Fig-8].

A 56-year-old female patient who came to emergency department for breathlessness showed normal appearance of aortic wall at the

\begin{tabular}{|c|c|c|c|c|c|}
\hline \multirow[b]{2}{*}{ Test result variable (s) } & \multirow[b]{2}{*}{ Area } & \multirow[b]{2}{*}{$\begin{array}{l}\text { Std. error } \\
\text { (a) }\end{array}$} & \multirow[b]{2}{*}{$\begin{array}{l}\text { Asymptotic } \\
\text { sig.(b) }\end{array}$} & \multicolumn{2}{|c|}{$\begin{array}{c}\text { Asymptotic } \\
95 \% \text { confidence } \\
\text { interval }\end{array}$} \\
\hline & & & & $\begin{array}{l}\text { Lower } \\
\text { bound }\end{array}$ & $\begin{array}{l}\text { Upper } \\
\text { bound }\end{array}$ \\
\hline Aorti ring $(\mathrm{HU})$ & 0.603 & 0.058 & 0.081 & 0.489 & 0.716 \\
\hline $\begin{array}{l}\text { Interventricular septum } \\
\text { HU AVG }\end{array}$ & 0.963 & 0.017 & 0.000 & 0.929 & 0.997 \\
\hline
\end{tabular}

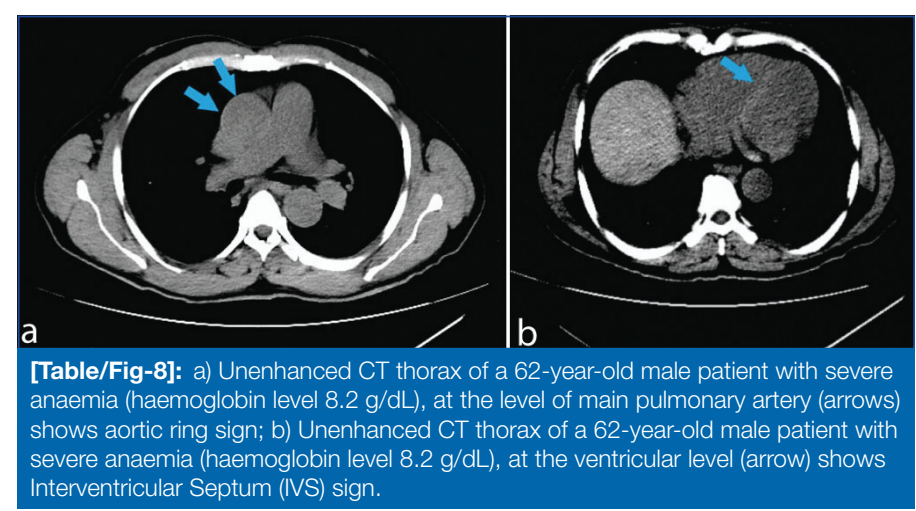

level of main pulmonary artery and at the ventricular level showed normal myocardium. Her plasma haemoglobin levels were found to be 13.2 g/dL, within normal range [Table/Fig-9].

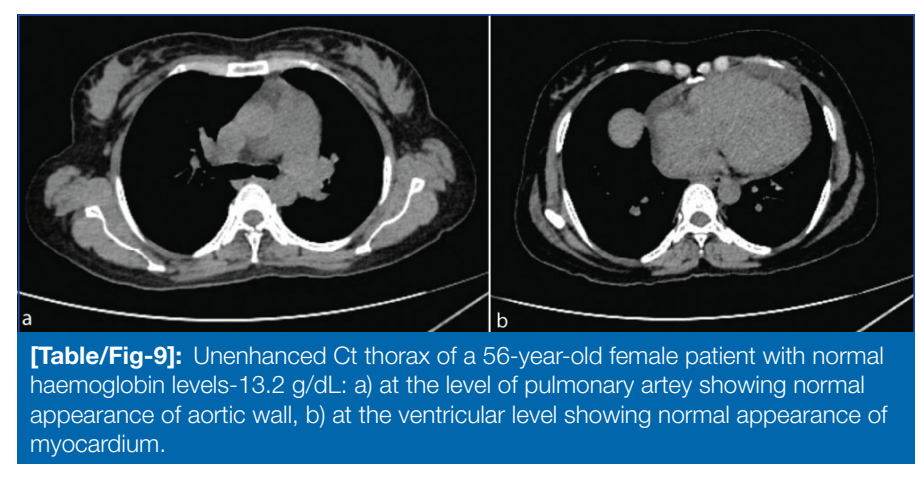

\section{DISCUSSION}

The prevalence of anaemia, which is generally considered to be low, has been recently shown to be more common. Prevalence of anaemia is well known among critical and oncology patients but the incidence of anaemia among aged people is rather four to six fold greater than suspected. Therefore, recognition and treatment of anaemia is important as when left untreated, is responsible for increased risks of morbidity, mortality, and long hospital stay. Despite these facts, however, anaemia remains neglected and undertreated diagnosis.

In the present study, despite a sensitivity of $96.61 \%$ for the dense IVS, this radiological sign disclosed a modest specificity of $80.49 \%$. Whereas, the aortic ring sign revealed a sensitivity of $84.75 \%$ against $73.17 \%$ specificity. This lower specificity of the aortic ring sign can be attributed to the existence of faint calcification which are encountered in pre-existing atherosclerotic plaques, which in turn are known to appear dense on unenhanced CT.

Lan $\mathrm{H}$ et al., studied that for diagnosing anaemia calculating the difference in CT attenuation between the IVS and the LV cavity was definitely superior to measuring the CT attenuation of the LV cavity alone [6].

Kamel EM et al., investigated the diagnostic value of unenhanced MDCT in anaemic patients and revealed that the aortic ring sign was more sensitive than the IVS sign for anaemia detection (84\% vs. $72 \%$ ), whereas this latter sign was more specific (100\% vs. 92\%) [4].

Patil NG et al., observed that CT attenuation value of aortic ring was more sensitive with a good correlation ( $r=0.63)$ and the IVS sign was more specific in detection of anaemia. They concluded 
that the attenuation values of aorta, aortic ring sign and IVS sign on unenhanced CT thorax establish an alternative basis in the assessment of anaemia [9].

Zhou $\mathrm{QQ}$ et al., revealed that an obvious parallel correlation of haemoglobin concentration and CT attenuation of IVS-LV occurred (the determination coefficient was 0.818; $\mathrm{p}<0.001$ ). The threshold of CT attenuation of IVS-LV was low, the specificity for diagnosing mild anaemia was low, while the sensitivity was very high and once the CT value was more than $13.5 \mathrm{HU}$ the sensitivity and specificity for diagnosing severe anaemia in all gender were good $(94.7 \%$ and $83.6 \%$ in male; $82.4 \%$ and $84.6 \%$ in female) [Table/Fig-10]. They concluded that the CT attenuation of IVS-LV could predict the severity of anaemia with good sensitivity and specificity, which could add value to clinical practice and more importantly facilitating patient care as hematologic laboratory investigations are lacking [10].

\begin{tabular}{|l|c|c|c|}
\hline IVS-LV HU value & Gender & Sensitivity (\%) & Specificity (\%) \\
\hline $5.5-9.5$ & $\mathrm{M}$ & 100 & 87.1 \\
\hline $4.5-8.5$ & $\mathrm{~F}$ & 100 & 87.1 \\
\hline $9.5-13.5$ & $\mathrm{M}$ & 92.9 & 74.8 \\
\hline $8.5-13.5$ & $\mathrm{~F}$ & 93.9 & 60 \\
\hline$>13.5$ & $\mathrm{M}$ & 94.7 & 83.6 \\
\hline$>13.5$ & $\mathrm{~F}$ & 82.4 & 84.6 \\
\hline
\end{tabular}

(Adapted from [10]).

This study revealed that anaemia can be predicted by measuring the CT attenuation of the IVS and on comparison made between the diagnostic accuracy of subjective observation methods (aortic ring sign or interventricular septal sign) with objective quantitative analysis, it is revealed that IVS sign is better at detection of anaemia on unenhanced CT.

However, non visualisation of the IVS did not necessarily exclude the presence of anaemia in males or females. Using a cut-off value of $38.15 \mathrm{HU}$ for IVS hyperdensity, the study yields a sensitivity and specificity of $96.61 \%$ and $80.49 \%$, respectively. Although, in patients, for example who are diagnosed with glycogen and iron storage disorders and require multiple blood transfusions resulting in iron overload, might display an increase in the IVS hyperdensity on CT inspite of presence of normal haemoglobin levels. We did not encounter any patients with glycogen or storage disorders in this study.

\section{Limitation(s)}

This is operator dependent study, hence more prone to error due to inter-observer variability. The false negative values can be obtained in patients with mild anaemia. False positives might also occur with visualisation of hyperdense IVS and diagnosis of anaemia will be misinterpreted.

\section{CONCLUSION(S)}

The results demonstrated significant correlation between the haemoglobin values and hyperdense IVS. This study also concludes that IVS sign is more sensitive and specific in diagnosing anaemia when compared with aortic ring sign. This provides an easy means to detect anaemia on non enhanced chest CT and the diagnosis of anaemia should be suggested whenever the IVS is visualised on unenhanced CT. Since, use of CT has been increasingly been done in cases of trauma in emergency department, merely presence of hyperdense IVS can give a clue to diagnosis of blood loss causing anaemia which further helps in patient management and outcome. Furthermore, during routine CT chest examinations done for other pathologies, visualisation of hyperdense IVS could be used to suggest anaemia diagnosis and further evaluation for the same will help in patient management.

\section{REFERENCES}

[1] Stillman AE, Oudkerk M, Ackerman M, Becker CR, Buszman PE, De Feyter PJ, et al. Use of multidetector computed tomography for the assessment of acute chest pain: A consensus statement of the North American Society of Cardiac Imaging and the European Society of Cardiac Radiology. The International Journal of Cardiovascular Imaging. 2007;23(4):415-27.

[2] Powell Jr WJ, Wittenberg J, Dinsmore RE, Miller SW, Maturi RA. Definition of cardiac structures using computerized tomography in isolated arrested and beating canine hearts. The American Journal of Cardiology. 1977;39(5):690-96.

[3] Doppman JL, Rienmuller R, Lissner J. The visualised interventricular septum on cardiac computed tomography: A clue to the presence of severe anemia. Journal of computer assisted tomography. 1981;5(2):157-60.

[4] Kamel EM, Rizzo E, Duchosal MA, Duran R, Goncalves-Matoso V, Schnyder P, et al. Radiological profile of anemia on unenhanced MDCT of the thorax. European Radiology. 2008;18(9):1863-68.

[5] Foster M, Nolan RL, Lam M. Prediction of anemia on unenhanced computed tomography of the thorax. Journal-Canadian Association of Radiologists. 2003;54(1):26-30.

[6] Lan H, Nishihara S, Nishitani H. Accuracy of computed tomography attenuation measurements for diagnosing anemia. Japanese Journal of Radiology. 2010;28(1):53-57

[7] Title RS, Harper K, Nelson E, Evans T, Tello R. Observer performance in assessing anemia on thoracic CT. American Journal of Roentgenology. 2005;185(5):1240-44

[8] Di Giandomenico E, Genovesi N, Sciarra R, Angelone T, Toppetti A. Quantitative evaluation of blood in vivo with computed tomography. La Radiologia Medica. 1993;85(4):416-20.

[9] Patil NG, Mehta C, Sehgal S, Patel J, Abhishek S. Correlation of anaemia with attenuation values on unenhanced CT of thorax. Journal of Evolution of Medica and Dental Sciences. 2017;6(17):1309-13.

[10] Zhou QQ, Yu YS, Chen YC, Ding BB, Fang SY, Yang X, et al. Optimal threshold for the diagnosis of anemia severity on unenhanced thoracic CT: A preliminary study. European Journal of Radiology. 2018;108:236-41. PMID: 30396662

PARTICULARS OF CONTRIBUTORS:

1. Junior Resident, Department of Radiodiagnosis, Father Muller Medical College and Hospital, Mangalore, Karnataka, India.

2. Senior Resident, Department of Radiodiagnosis, Father Muller Medical College and Hospital, Mangalore, Karnataka, India

3. Senior Resident, Department of Radiodiagnosis, Father Muller Medical College and Hospital, Mangalore, Karnataka, India.

NAME, ADDRESS, E-MAIL ID OF THE CORRESPONDING AUTHOR:

Anusha Mahalawat,

Mangalore, Karnataka, India.

E-mail: anusha3693@gmail.com
PLAGIARISM CHECKING METHODS: JJain Het al.J

- Plagiarism X-checker: Nov 07, 2020

- Manual Googling: Jan 21, 2021

- iThenticate Software: Feb 20, 2021 (19\%)
ETYMOLOGY: Author Origin

\section{AUTHOR DECLARATION:}

- Financial or Other Competing Interests: None

- Was Ethics Committee Approval obtained for this study? Yes

- Was informed consent obtained from the subjects involved in the study? Yes

- For any images presented appropriate consent has been obtained from the subjects. Yes
Date of Submission: Nov 06, 2020

Date of Peer Review: Dec 30, 2020

Date of Acceptance: Mar 13, 2021

Date of Publishing: Jul 01, 2021 